\title{
TRABALHO E PRODUÇÃO DE SAÚDE: PRÁTICAS DE LIBERDADE E FORMAS DE GOVERNAMENTALIDADE
}

\author{
HEALTH PRODUCTION: \\ PRACTICES OF FREEDOM AND GOVERNMENTALITY
}

\author{
Anita Guazzelli Bernardes \\ Universidade Católica Dom Bosco, Campo Grande, Brasil
}

Eduardo Cavalheiro Pelliccioli

Universidade Federal do Mato Grosso do Sul, Campo Grande, Brasil

Neuza Maria de Fátima Guareschi

Pontifícia Universidade Católica do Rio Grande do Sul, Porto Alegre, Brasil

\section{RESUMO}

Este texto tem como objetivo analisar o conceito de produção de saúde, no campo da Saúde Coletiva, como o nó de uma rede de cuidados. Nó porque a produção de saúde costura a noção de sujeito na saúde com os cuidados na saúde em um campo de estranhamento. Para fazer essa discussão, este texto partirá do trabalho na saúde como um conjunto de práticas de governamentalidade que encontram na produção de saúde a conformação de práticas de liberdade. As ferramentas conceituais utilizadas para essa discussão partem da proposição foucaultiana sobre uma ontologia do presente: subjetividade, poder e verdade. Esses operadores conceituais serão articulados às ideias de trabalho afetivo e potência de vida. Como exercícios do pensamento, tomam-se, então, as discussões no campo da Saúde Coletiva: integralidade, produção de saúde, cidadania e trabalho na saúde.

Palavras-chave: produção de saúde; governamentalidade; práticas de liberdade; integralidade; saúde coletiva.

\begin{abstract}
This text aims at analyzing the concept of health production, in the field of Collective Health, as a knot in a care net. It is a knot because the production of health links the notion of subject in health to health care in a suspicion field. This text takes health work as a set of governmentality practices that find freedom practices in health production. The conceptual tools used in this discussion have departed from the Foucauldian proposition about ontology of present: subjectivity, power and truth. These conceptual operators have been articulated with ideas of affective work and life power. As exercises of thought, discussions in the field of Collective Health have been considered, such as: integrality, health production, citizenship, and health work.
\end{abstract}

Keywords: health production; governmentality; freedom practices; integrality; collective health.

Este texto tem como objetivo analisar o conceito de produção de saúde, no campo da Saúde Coletiva, como o nó de uma rede de cuidados. Nó porque é nesse território que as práticas em saúde se encontram com aquilo que não é da ordem das taxionomias, e sim da produção de vida. Nó porque a produção de saúde costura a noção de sujeito na saúde com os cuidados na saúde em um campo de estranhamento. Para fazer essa discussão, este texto partirá do trabalho na saúde como um conjunto de práticas de governamentalidade que encontram na produção de saúde a conformação de práticas de liberdade.
As ferramentas conceituais utilizadas para essa discussão partem da proposição foucaultiana sobre uma ontologia do presente: subjetividade, poder e verdade. Esses operadores conceituais serão articulados às ideias de trabalho afetivo e potência de vida. Como exercícios do pensamento, tomam-se, então, as discussões no campo da Saúde Coletiva: integralidade, produção de saúde, cidadania e trabalho na saúde.

Em um primeiro momento, será discutido o trabalho na saúde como uma arte de governamentalidade e estratégias biopolíticas para relacioná-lo ao trabalho afetivo. A partir disso, o texto volta-se para a reflexão 
sobre integralidade e práticas em saúde no campo da Saúde Coletiva mediante a articulação dos conceitos biopsicossocial e potência de vida. O texto é finalizado com considerações que pronunciam a relação entre potência de vida e produção de saúde.

\section{Trabalho na saúde e estratégias de governamentalidade}

Foucault (1999), em texto intitulado "Direito de morte e poder sobre a vida", faz uma análise das modificações que ocorrem quando uma organização social deixa de ser absolutista e passa a ser um Estado-nação. Focaliza, nessa discussão, uma genealogia do poder em termos de estratégias de governo relativas a uma organização monárquica ou a uma federação. Foucault (1999) referia-se ao absolutismo, forma de governo característica das monarquias, como uma figura jurídica em que o poder do rei se constituía como instância de confisco, de direito de apropriação de riquezas e de corpos. Nesse caso, não se tratava de objetivar um sujeito como um corpo político, na medida em que a soberania se dava sobre um território, ou seja, a vida não se encontrava no mesmo campo que o direito. Essa formulação é pensada por Foucault (1999) como um poder soberano que, antes de tudo, se apodera da "vida para suprimi-la" (p. 128).

Com a formação da figura jurídica do Estadonação, característica de repúblicas organizadas a partir do século XVIII, engendra-se outro mecanismo de poder que vai justamente articular a vida dentro do campo do direito e, com isso, objetivar a população como um corpus político. Essa modificação em termos de estratégias de poder passa a investir na vida não mais como forma de confisco, mas como modo de incitamento, de fazê-la crescer e ordená-la. A vida entra na esteira da gestão de Estado em sua dimensão biológica. É o que se nomeia de biopoder e estratégias biopolíticas (Foucault, 1999). A vida da população constitui-se como estratégia de governo, ou seja, como uma estratégia de governamentalidade:

à multiplicidade dos homens, não na medida em que eles se resumem em corpos, mas na medida em que ela forma, ao contrário, uma massa global, afetada por processos de conjunto que são próprios da vida, que são processos como o nascimento, a morte, a produção, a doença, etc. (Foucault, 2005, p. 289).

A governamentalidade constitui-se como uma arte de governo que tem como foco a população e que a torna um termo da própria experiência de Estado. A população torna-se foco do poder em razão de seus efeitos econômicos específicos: "epidemias, expansões endêmicas, a espiral do trabalho e da riqueza" (Foucault, 2003a, p. 299).
O trabalho constitui-se, então, como uma forma de governo das populações, tanto em termos de produção de riqueza para o desenvolvimento da Nação, de filiação social para a população, quanto como uma forma de controle, de investimento nas formas de vida da população mediante políticas públicas. Essa "arte de governar" tem como característica a cisão do corpus da população, na medida em que essa é tomada como um conjunto heterogêneo: aqueles em que o poder investe para fazer viver e aqueles que o poder considera como vidas indignas de serem vividas. Isso produz bolsões de pobreza que não cessam de interrogar as estratégias de poder de um Estado-nação, pois a biopolítica para essas vidas apresenta-se como um plano de bifurcação, tanto se torna um procedimento de filiação social quanto, ao não alcançar certos grupos sociais, os deixa morrer, ao invés de fazer viver:

É como se toda a valorização e toda a politização da vida ... implicasse necessariamente uma nova decisão sobre o limiar além do qual a vida cessa de ser politicamente relevante, é então somente vida sacra e, como tal, pode ser impunemente eliminada (Agamben, 2007, p. 146)

Segundo Agamben (2007), trata-se de outra configuração do poder soberano, ou seja, uma soberania sobre o direito à vida, que encontra suas justificativas no desenvolvimento de uma nação, e não na figura privada do soberano. A soberania na biopolítica refere-se a uma população sobre a outra a partir daquilo que é forjado como racismo de Estado. É uma forma de politização da vida, é uma aposta política nas formas de viver. A biopolítica moderna apresenta uma necessidade perene de redefinir um limiar de articulação e separação entre aquilo que está dentro e aquilo que está fora. Esse limiar toma a vida como critério no que diz respeito às formas de viver: uma vida autêntica e uma vida nua "privada de todo o valor político" (Agamben, 2007, p. 139).

Dessa forma, a biopolítica utiliza-se de uma racionalidade que liga os "Direitos do Homem" aos direitos do cidadão, porém, segundo Agamben (2007), na própria "Declaração dos direitos do homem e do cidadão", formulada em 1789 por La Fayette, não existe uma definição precisa em que os dois termos "homem" e cidadão - se apresentariam como realidades distintas ou unitárias, ou seja, a definição de "homem"1 pressuporia a definição de cidadão ou que se trataria de termos autônomos. O cidadão é aquele que, por uma questão de nascimento, se torna um sujeito de direitos de uma determinada nação; desse modo, "as declarações dos direitos devem então ser vistas como o local em que se efetua a passagem da soberania régia de origem divina à soberania nacional" (Agamben, 2007, p. 135). Entretanto, esse critério de natividade, conformado por uma biopolítica que estenderia o direito a qualquer 
sujeito nascido em um determinado território, divide os cidadãos, define um limiar de separação entre as formas de viver: aquelas vidas consideradas indignas de serem cidadãs e as vidas representativas de uma suposta identidade nacional. A biopolítica viria, então, para recodificar as formas de vida que se encontram ao mesmo tempo no território nacional, mas às margens do Estado-nação, de modo a capturar aquilo mesmo que ela produz: vidas indignas. Essas vidas indignas são iluminadas não em razão de cidadania da natividade, mas em razão dos índices de desenvolvimento de uma nação e de estratégias de controle das populações.

Esse investimento das biopolíticas diz respeito a uma arte de governar os indivíduos em suas relações: "são os homens em suas relações com essas outras coisas que são os costumes, os hábitos, as maneiras de fazer ou de pensar" (Foucault, 2003a, p. 290). Isso configura um conjunto de práticas que encontram no campo da saúde uma estratégia de governamentalidade por meio de políticas públicas. Essas estratégias levam em consideração os indivíduos no que tange aos acontecimentos de conjunto, como acidentes e desgraças - fome, mortalidade, epidemias - e também riqueza e prosperidade. As práticas em saúde tornam-se um modo de governo das populações, de controle e investimento no indivíduo e suas relações em termos de formas de vida inscritas em processos biológicos.

Essa forma de governar os indivíduos em seus efeitos de conjunto - população - organiza-se em torno de uma razão de Estado, em que a arte de governo se liga à emergência de problemas próprios da população. Uma dessas emergências diz respeito ao campo da saúde: epidemias, mortalidade, pobreza. A relação entre essas três dimensões constitutivas da vida da população será foco de estratégias de saúde que investirão na vida, não no sentido de aperfeiçoá-la de modo geral, mas no sentido de administrá-la, de governá-la a partir daquilo que se considera, mediante um racismo de Estado, que deve viver e aquilo que se deixa morrer. A pobreza será correlacionada à doença e objetivada como uma forma endêmica da Nação, portanto, ao trabalho na saúde caberá conter o efeito de contaminação da Nação por meio da pobreza. Isso se articula nos movimentos higienistas e eugenistas. O higienismo, como um desdobramento da medicina social, articula-se ao eugenismo, como purificação da raça, tornando-se uma estratégia de governamentalidade que encontra no trabalho na saúde uma forma de materialização dessa racionalidade de Estado. No Brasil, terá como expressão o sanitarismo campanhista, característico das primeiras décadas do século XX, e o desenvolvimentista, engendrado pelo investimento no crescimento industrial a partir das décadas de quarenta/cinquenta.

A eugenia pressupunha a articulação de algumas categorias: população, qualidade, território, nação, raça
- aquilo que Foucault (2005) nomeia como gabarito de inteligibilidade. A eugenia, como forma de racismo, assegura ao Estado a função de controle biopolítico. Nesse caso, o racismo de Estado assegura o território, a nação e a qualidade mediante o investimento na população e na raça constitutiva dessa população, "portanto, o racismo é ligado ao funcionamento de um Estado que é obrigado a utilizar a raça ${ }^{2}$, a eliminação das raças e a purificação da raça para exercer seu poder soberano" (Foucault, 2005, p. 309).

A eugenia encontra no racismo de Estado sua forma de expressão, bem como sua justificativa: o desenvolvimento/soberania da Nação. Essa forma de soberania da Nação vai encontrar na saúde um dispositivo biopolítico voltado para a população.

Entretanto, a eugenia pensada na série população, qualidade, território, nação e raça modifica-se. $\mathrm{Na}$ contemporaneidade, o que encontramos é mais uma individualização de práticas eugênicas ${ }^{3}$, na medida em que cabe ao indivíduo a escolha do que quer ser. Nesse caso, a eugenia conforma-se como um ato individual, e não como política de Estado; um ato de escolhas, aspirações e desejos do indivíduo relativos à vida, e não à raça. Desloca-se o exercício de soberania do Estado para o exercício de soberania do indivíduo, o sujeito de direitos. O sujeito de direitos pode/deve escolher aquilo que qualificaria melhor a sua raça. As estratégias de poder também aqui encontram na saúde um modo de controle mediante a engenharia genética.

A reforma sanitária, no Brasil, vem justamente na esteira de movimentos sociais da década de setenta que provocam novas formas de o poder exercer-se sobre a vida. Quer dizer, a reforma sanitária ilumina existências que eram consideradas vidas indignas como forma de tornar a figura jurídica do sujeito de direito do Estado-nação extensiva a toda a população, dando visibilidade para a precarização da vida, mediante as políticas higienistas e eugenistas. A reforma sanitária objetiva o direito à saúde como condição para a cidadania plena da população, e não uma forma de separação entre cidadania autêntica e cidadania de "segundo escalão" (Agamben, 2007). Entretanto, é importante marcar que a reforma sanitária não se trata apenas de uma discussão do campo do direito; é, sim, um movimento que modifica as maneiras de conceber a relação do Estado com a população em termos de condições e novas possibilidades de vida.

A reforma sanitária articula, entre outras dimensões, a ideia de igualdade de direitos em termos de acesso a bens materiais e sociais mediante a constituição da saúde como suporte social. É uma resposta política a uma biopolítica que cingia o tecido social. Nesse sentido, o trabalho na saúde passa a constituir-se como uma instância de utilidade social no que tange às transforma- 
ções biopolíticas voltadas para a cidadania, e não apenas controle epidêmico e endêmico que definia que formas de vida estavam dentro e quais estavam fora. Desse modo, o trabalho na saúde passa a se inscrever como uma dimensão das políticas da vida voltadas para

a garantia, pelo Estado, de condições dignas de vida e de acesso universal e igualitário às ações e serviços de promoção, proteção e recuperação da saúde, em todos os seus níveis, a todos os habitantes do território nacional, levando ao desenvolvimento pleno do ser humano em sua individualidade (Presidência da República Federativa do Brasil, 2005).

O trabalho na saúde configura-se, a partir disso, como política pública que se formula em movimentos sociais produzidos por procedimentos de governamentalidade. O trabalho na saúde engendra-se de um campo de lutas por imposições de sentidos que modificam a forma como a população figura em termos de práticas de liberdade. Ou seja, o trabalho na saúde faz parte de um campo político, e não apenas de benesse social. $\mathrm{O}$ acesso às condições de saúde é uma questão de direito, e não de privilégio, ou deveria ser. Marcar isso significa olhar as modificações em termos de práticas de cuidados.

Essas modificações dizem respeito a uma genealogia das práticas em saúde que vão migrando do campo de ações caritativas/higienistas/eugenistas voltadas para a população, da medicina clássica que focava o corpo individual, para o campo do direito à saúde, do direito à vida e à cidadania. Nesse embate, o que entra em jogo é a forma como a política toma a vida: a vida pensada em termos de multiplicidade de formas de viver, e não como forma biológica. Quando tomamos a vida como condição do vivente, e não como multiplicidade de formas viventes, as práticas em saúde conformam-se como ações voltadas para fazê-lo viver ou deixá-lo morrer. Quando a vida é tomada como multiplicidade de formas, as práticas em saúde deparam-se com as condições de vida, e não apenas com o organismo do ser vivente. As condições de vida referem-se à objetivação de corpos políticos, e não a corpos biológicos. Nesse sentido, o reconhecimento do trabalho na saúde reside na possibilidade de operacionalizar essa transformação do sujeito organismo em sujeito político, do indivíduopopulação em cidadão.

Ao se articular o trabalho na saúde com a cidadania e as formas de viver, volta-se ao que é assinalado por Hardt (2003) como trabalho afetivo. Para considerar essa dimensão afetiva, é necessário articular o trabalho na saúde com a objetivação de que "a saúde das pessoas é um assunto que se refere primordialmente a elas próprias" (Caponi, 2003, p. 72). Ou seja, é preciso inscrever um sujeito-político, e não organismo, nas práticas em saúde. Isso significa migrar as biopolíticas da vida como forma biológica para a vida como mul- tiplicidade de formas e, nesse movimento, considerar o outro na saúde como uma dimensão de alteridade/ estranhamento que afeta a própria constituição de um campo de racionalidade técnica. A administração das formas de viver implicará, nesse sentido, estratégias biopolíticas que articulem o humano na sua dimensão afetiva. Por dimensão afetiva, entende-se o exercício de afetar e ser afetado pelo outro. Significa o que Ortega (1999) assinala como uma experiência da subjetividade em que o outro não é submissível a si mesmo, e sim uma experiência da alteridade do outro.

\section{Trabalho afetivo}

O trabalho na saúde envolve duas dimensões do que hoje se compreende como grandes agrupamentos de categorias laborais: a prestação de serviços e o trabalho de rotina. A essas duas categorias, soma-se o que qualifica um trabalho na saúde: a relação com o outro. É essa particularidade do trabalho na saúde que o torna aquilo que hoje é nomeado como trabalho afetivo ou familial ou prestação de cuidados.

Como prestação de serviços e trabalho de rotina, o trabalho na saúde conforma-se como prática de utilidade social. Utilidade social quando pensado em relação ao direito, a uma atividade pública, a um ato social que não se confunde com uma atividade privada (Castel, 2004). O trabalho na saúde é uma prática eminentemente voltada para o outro que, a partir da Constituição de 1988, é forjado como um sujeito de direito. Ou seja, o trabalho na saúde entra na esteira de práticas sociais que, a partir da reforma sanitária, formulam a saúde como um direito e também como modo de acesso a possibilidades de vida. $\mathrm{O}$ acesso à saúde torna-se uma forma de filiação social em que o sujeito passa a ser objetivado pelo direito às condições de vida. Esse sujeito objetivado pelo trabalho na saúde migra de um território de existências indignas para um território de direito à existência.

O que se quer apontar com isso é que a saúde, ao articular-se ao campo do direito, na reforma sanitária, se torna um conjunto de práticas de utilidade social no que tange à iluminação de certas formas de vida que figuravam no campo das políticas públicas como vidas infames margeando o tecido social. Essas formas de vida existiam em termos de estatísticas referentes ao índice de desenvolvimento humano do país, ou seja, vidas que não tinham acesso à educação, saneamento, saúde, trabalho, etc. Vidas que se deixava morrer, vidas não dignas de serem vividas (Agamben, 2007). Isso significa, no campo da reforma sanitária, considerar que o direito à saúde é um direito à cidadania, ou seja, trata-se de uma estratégia política em termos de democracia e filiação social (Pinheiro, 2004). 
Além de utilidade social no que tange à conformação de um sujeito de direito, o trabalho na saúde é um trabalho afetivo, uma forma de trabalhar que produz serviços, conhecimento, comunicação, interações e contatos humanos, que mistura o que outrora havia sido separado por uma perspectiva moderna - material e imaterial. É uma forma de trabalhar chamada de modalidade corporal, pois produz redes sociais, produz comunidades: "As prestações de cuidados estão, com certeza, completamente imersas no corporal, no somático, mas os afetos que elas produzem são, não obstante, imateriais" (Hardt, 2003, p. 152). O trabalho afetivo, dessa forma, produz valor. Produz valor, pois a maneira como nos relacionamos com o outro nunca é neutra e traz consigo o modo como pensamos e cuidamos desse outro. O que está implicado nessa produção de valor do trabalho afetivo é que as relações humanas estão "inteiramente dominadas pelo capital e integradas a ele", segundo Hardt (2003, p. 153).

O que isso quer dizer é que o trabalho na saúde é aquilo que sobrepõe o corporal como dimensão exclusivamente material. $\mathrm{O}$ afeto que caracteriza o trabalho na saúde é ele mesmo responsável pelos sentidos que atribuímos aos cuidados em saúde, é uma dimensão ontológica do trabalho, "revela o trabalho vivo que constitui uma forma de vida" (Hardt, 2003, p. 156) inscrita e produzida pela biopolítica. Ou seja, mais do que uma técnica aplicada sobre o corpo do outro, é a relação que estabelecemos com esse outro que sustenta a qualidade da nossa técnica no que se refere à relação de produção entre afeto e valor. Desse modo, a base de qualquer técnica em saúde é a relação que se estabelece com o outro quando objetivamos o trabalho na saúde a partir de um princípio de integralidade. Um princípio que se apresentaria na contramão da relação entre capital e trabalho. Um princípio que entraria na esteira das tecnologias que modificam a lógica do trabalho na saúde: "A saúde é um direito fundamental do ser humano, devendo o Estado prover as condições indispensáveis ao seu pleno exercício" (Presidência da República Federativa do Brasil, 2005). A interrogação, então, é: de que modo se articula um princípio de integralidade e alteridade com a relação entre afeto e valor produzida pelo capital no campo da saúde?

\section{Integralidade e práticas em saúde}

A noção de produção de saúde torna-se mais compreensível quando a pensamos em relação ao conceito de integralidade na saúde. A integralidade permite-nos compreender que aquilo que é efetivo em termos de qualidade da atenção, necessariamente, envolve o humano não como organismo dividido em especialidade e técnicas, mas como sujeito história de muitas vidas.
Dito de outro modo, pensar em integralidade é situar o humano na sua condição humana, como ser que vive, que fala, que trabalha, e não exclusivamente em sua condição orgânica. Essa condição humana apenas pode ser pensada quando integramos o sujeito na história, ou seja, as formas de viver, mediante as quais nos objetivamos como humanos, são forjadas por condições de possibilidades sócio-históricas nas quais esse sujeito se encontra. Essas condições, na contemporaneidade, dizem respeito ao desenvolvimento integral do humano, isto é, não se trata de tomar a doença, mas o sujeito enfermo inserido em redes sociais: o território, a família, as instituições (Secretaria Municipal de Saúde, 2007). Pensar esse outro da saúde como sujeito é construir um campo de cuidados que tem como base a dimensão imaterial da qual falávamos anteriormente: o trabalho afetivo.

A relação entre trabalho afetivo e integralidade é possível pela racionalidade de que, mais do que procedimentos e técnicas utilizados na saúde, deve configurar-se uma dimensão de cuidado com o outro, de modo a se enfatizar justamente essa possibilidade relacional, e não apenas técnica (Pinheiro \& Guizardi, 2006). É uma forma de colocar em análise a relação do Estado com os serviços de saúde no que tange ao deslocamento de uma racionalidade de prestação de serviços e mercado para o cuidado em saúde como vínculo e suporte social. O conceito de integralidade transforma a própria experiência de Estado: de soberania da Nação para suporte social de possibilidades de vida. Aqui, a biopolítica de Estado encontra-se com a potência de vida da população. É dessa provocação de potências de vida, de distintas formas de viver, que se articulam práticas de integralidade.

A integralidade é considerada um conceitoproblema polissêmico. A polissemia, nesse caso, não se refere a um objeto que contemplaria múltiplos sentidos, mas a um campo de articulações e proposições que conforma diferentes figuras: relações entre equipe e usuários, organização dos processos de trabalho, respostas governamentais às demandas espontâneas, entre outras (Mattos, 2001). A integralidade tanto conforma objetos como interdisciplinaridade e intersetorialidade quanto as próprias formas de subjetivação na saúde: usuários, gestores, trabalhadores.

O que acontece é que esse princípio de integralidade apresenta um plano de bifurcação: por um lado, o integral refere-se ao que se nomeia de figura "biopsicossocial"; por outro lado, articula-se a uma figura de potência, sem um axioma que o predefina, a uma alteridade absoluta. A primeira forma de subjetivação configura-se naquilo que é engendrado por um poder sobre a vida. Na segunda forma, encontramos a resposta política ao poder sobre a vida: "a potência política da vida, na medida em que faz variar suas formas e 
reinventa suas coordenadas de enunciação" (Pelbart, 2003 , p. 13). Isso não quer dizer que existam apenas duas formas, mas que essas formas, ao se bifurcarem, multiplicam-se, ao mesmo tempo em que não são excludentes uma da outra.

\section{Integralidade e o biopsicossocial}

Quando operamos com essa figura existencial "biopsicossocial", temos como formas de intervenção, na saúde, o tratamento, a reabilitação e a prevenção quer dizer, a integralidade não diz respeito apenas à constituição de um sujeito, mas também às ações sobre esse sujeito. Essas ações devem estar integradas, bem como articuladas com outras políticas públicas.

Essas instâncias de cuidado com a saúde criam a necessidade de um sujeito predefinido. $\mathrm{O}$ "biopsicossocial" é ele próprio um marcador de instâncias distintas constitutivas do sujeito. Ou seja, estratifica o humano em três dimensões que se tornam o "fundamento" das práticas em saúde. Ao se planificar o humano, dessa forma, considera-se que existe uma dimensão material, que é o corpo, e uma imaterial, que é o psiquismo; a forma de relacionar essas duas instâncias estaria no social, ou seja, no plano das relações humanas. Esse modelo de estratificação humana ampara-se em uma racionalidade herdeira do pensamento moderno, em que o visível, o apreensível é a dimensão considerada material, enquanto que o imaterial seria objetivado como a da ordem do afetivo e relacional. Não se trata mais de um dualismo mente/corpo, mas de um dualismo material/imaterial que, em um certo sentido, força uma disjunção daquilo que o próprio trabalho na saúde tenta amalgamar. Corpo, psiquismo e relações humanas são, já de um bom tempo, objetos de governo. Agora, a saúde torna-os correlatos, de modo a um implicar o outro. Isso significa um modelo ideal de humano circunscrito a três dimensões. Aquele humano do Iluminismo, objetivado como um sujeito da razão, agora se torna um humano iluminado pela integralidade do biopsicossocial.

Isso implica consumirmos um modo existencial, uma forma de vida que por si só é herdeira de um território existencial biomédico, ou seja, é uma forma de resposta política do poder sobre a vida na medida em que ela multiplicou suas formas. Aquele corpo organismo, ao se multiplicar em razão de uma potência política da vida, provocou novas estratégias de um poder sobre a vida: o biopsicossocial. Desse modo, o trabalho na saúde constitui-se como uma forma de governo, como uma biopolítica que investe na produção desse sujeito biopsicossocial a partir de tecnologias como a cura, a reabilitação e a prevenção. Essas três dimensões da atenção à saúde são o que poderíamos nomear de território seguro das ações em saúde.
Tal segurança reside em taxionomias da subjetividade, dos comportamentos, das relações humanas. Essas taxionomias operacionalizam e articulam as enfermidades aos riscos de agravos mediante "recomendações normativas de mudanças de hábitos" (Czeresnia, 2003, p. 45). O biopsicossocial encerra a subjetividade em um campo em que o outro é submissível a si mesmo. Isso quer dizer que a relação entre o eu e o outro, na saúde, considera esse outro como um eu estratificado por um plano de reconhecimento. Esse reconhecimento refere-se a uma elaboração do outro anterior ao que esse outro provocaria em qualquer forma de circunscrição de sentidos, ou seja, esse outro como uma alteridade absoluta. Entretanto, essa noção de alteridade absoluta torna-se impraticável quando o objeto da saúde é um sujeito enfermo. Essa forma de subjetivação - sujeito enfermo - implica, por si só, uma captura do outro e um plano de codificação. Poderíamos, então, interrogar: de que modo seria possível uma prática de cuidados se não operássemos tanto com a noção de um eu quanto com uma racionalidade constituída por explicações e justificativas para a saúde e seus agravos? Como seria possível a cura, o tratamento e a prevenção se não estivesse disponível, em termos de racionalidade técnica baseada em um conhecimento da história natural, um campo de visibilidade e dizibilidade da saúde e seus agravos?

Mas esse campo de visibilidade e dizibilidade na saúde produz uma forma de subjetivação, produz um eu que torna possível as ações em saúde segundo um modelo de reconhecimento do outro não em termos de alteridade, mas de taxionomia. Esse eu é uma figura preexistente no campo da saúde. A relação de intersubjetividade, nesse caso, pressupõe lugares, posições, status de submissão. A racionalidade técnica implica um assujeitamento ao olhar do técnico em saúde. Esse assujeitamento dá-se em relação à figura biopsicossocial, a uma ontologia de quem somos na saúde.

\section{Integralidade e potência de vida}

A bifurcação do princípio de integralidade para um plano de potência de vida, por outro lado, encaminhanos para um campo de experiência em que o outro não é passível de submissão ao si mesmo (Ortega, 1999). Ou seja, o outro é experimentado em sua alteridade, e não como um eu. O outro se apresenta em uma absoluta inacessibilidade. Isso significa, para uma racionalidade técnica, a abertura para um vazio.

Abertura para um vazio na medida em que, ao tentarmos apreender a alteridade, ela escapa, apresentase como potência, e não como forma. $\mathrm{O}$ que se quer pensar com isso é como articular o princípio de integralidade com o de produção de saúde, que deveria 
figurar como parte da própria integralidade em saúde. É onde encontramos um nó, pois, ao tratar-se de um princípio, a integralidade conforma certa subjetividade. Ao conformar uma subjetividade, opera com um plano de prevenção, e não com um plano de produção. Isto é, quando a integralidade se torna um agenciamento na saúde, produzem-se unidades de sentidos. Essas unidades de sentidos são possíveis em um plano de ações de prevenção, tratamento e reabilitação, mas, no que tange à produção de saúde, essas unidades se esvaem, pois, como já foi escrito, a produção abre para a potência, e a potência é força, e não forma, ou seja, é transição e perdição, é uma zona fronteiriça.

Isso significa pensar que a produção de saúde interroga a própria integralidade em saúde. A produção em saúde não é o avesso da integralidade, mas o acaso de seu desenrolar, de modo a tornar-se uma potência política da vida, ou uma biopotência em relação à biopolítica. A produção em saúde não é uma grande recusa (Foucault, 2004), e sim um conjunto de práticas de liberdade em que o que produz esse movimento é a alteridade, e não uma identidade.

A produção em saúde, quando articulada à biopotência, desterritorializa o "biopsicossocial", na medida em que agencia novos laços, desejos, crenças, associações e formas de cooperação. Isso significa, no campo da saúde, a abertura ao risco. Risco de uma potência que escapa à capacidade preditiva da ciência. Risco de produção de novas formas de vida. Risco da alteridade. E isso é um risco para o campo da saúde.

O que acontece é que a pobreza, a periculosidade, na sua precariedade de subsistência, toma a vida como potência, isto é, como insistência. Insistência em criar novas formas. Insistência no risco de permanecer vivendo. Essa insistência joga as ações em saúde para o campo da produção em saúde, pois é essa insistência que escapa à prevenção. É essa insistência ao risco de potência que não encontra explicações no campo da saúde. Essa insistência é a alteridade em saúde. O que reporta, novamente, ao nó. Como operar com a produção em saúde quando ela traz consigo o risco? E o risco, no campo da saúde, é transformado em um provável, em um real? Como trabalhar em saúde sem ter um sujeito da saúde, e sim uma potência de vida?

\section{Potência de vida e produção de saúde}

Inocência, é a criança, e esquecimento; um novo começo, um jogo, uma roda que gira por si mesma, um movimento inicial, um sagrado dizer sim. Sim, meus irmãos, para o jogo da criação é preciso dizer um sagrado sim: o espírito, agora, quer sua vontade, aquele que está perdido para o mundo conquista o seu mundo (Nietzsche, 1998, p. 44).
A produção de saúde, entre outros conceitos, é aquilo que modifica necessariamente a forma como trabalhamos na saúde. É uma das linhas que nos permite ampliar e modificar o trabalho na saúde na medida em que não se trata apenas de tratamento, reabilitação e prevenção, mas de produção de possibilidades de vida. A produção em saúde é a figura da criança, da inocência, do esquecimento, como escreve Nietzsche, figura de potência pelo sagrado dizer sim. É a insistência da potência de vida que se afirma na produção de saúde.

Essa produção de possibilidades de vida é o nó na rede de saúde. Nó porque é justamente no âmbito da produção em saúde que o trabalho em saúde se encontra com aquilo que difere. Ou seja, é na produção de saúde que, como trabalhadores, nos deparamos com a diferença. Diferença de histórias de vida, diferença de possibilidades de vida. E a condição para pensar a diferença está na dimensão imaterial do trabalho em saúde. É essa dimensão que justifica a existência do SUS e que nos possibilita pensar no conceito que envolve o trabalho na saúde: potência de vida.

A potência de vida é um termo forjado pela filosofia, mas fundamental para pensar o trabalho na saúde a partir dos conceitos de trabalho afetivo, integralidade e produção de saúde. Potência de vida refere-se à ideia de que a vida é um permanente reinventar-se. Ou seja, existe algo em nós capaz de sempre criar novas formas de se agregar, de criar sentidos, de inventar dispositivos de valorização e autovalorização. Nas discussões de Arendt $(1989$, p. 28$)$, "a tarefa e a grandeza potencial dos mortais têm a ver com sua capacidade de produzir coisas - obras e feitos e palavras"; nisso reside a ideia de que os humanos não nascem para morrer, mas para recomeçar.

Operar com a produção de saúde não diz respeito a olhar para o querer-viver, mas para a afirmação da vida (Deleuze, 2006). E a afirmação da vida encontra-se não nas essências, como na forma biopsicossocial, mas nas circunstâncias, na variação das formas de existir. Essa variação das formas de existir relaciona-se à potência de agir. Essa potência de agir é provocada por aquilo que faz variar as formas de existir: o afeto. $\mathrm{O}$ afeto, segundo a discussão que Deleuze faz a partir de Spinoza, diz respeito ao

estado de um corpo considerado como sofrendo a ação de um outro corpo ... a afecção [affectio] é uma mistura de dois corpos, um corpo que se diz agir sobre outro, e um corpo que recolhe o traço do primeiro. Toda mistura de corpos é chamada de afecção (Deleuze, 2006, p. 5).

Nesse sentido, potência de vida e produção de saúde implicam uma relação entre afeto/afecção, potência de agir, variação das formas de existir. Isso é o que justamente escapa no campo da saúde, é aquilo que poderíamos chamar de um plano de produção de 
si mesmo não fora do campo da saúde, mas como uma variação estrangeira no próprio campo. É o território da invenção e da criação, o território da inocência. São práticas que Foucault (2004) nomeia de liberdade.

Essas práticas de liberdade são formas de negociação dentro das próprias biopolíticas, dentro das estratégias de governamentalidade. Essas práticas de liberdade não se apresentam como uma grande recusa à governamentalidade. Essas práticas de liberdade são forjadas pela condição mesma de afecção das biopolíticas sobre os corpos. São as variações das misturas produzidas pelas práticas em saúde. É um sagrado dizer sim. O risco, então, não se refere ao provável, mas à afirmação do improvável: da potência de vida. O risco é um risco para o trabalho na saúde, na medida em que o provoca/afeta a variar suas formas. O risco é da invenção/criação de novas possibilidades de vida.

Isso é percebido de maneira mais intensa quando olhamos para vidas completamente precarizadas. A potência de vida dá-se não no âmbito individual, mas no âmbito coletivo, e aqui voltamos ao trabalho afetivo que envolve a relação com o outro, a capacidade de produzir laços e redes sociais, de invenção de novos desejos e crenças, novas associações e formas de cooperação. Isso requer do trabalhador da saúde sua inteligência, sensibilidade, imaginação, criatividade, conectividade e afetividade - é a existência que é posta a trabalhar, e não apenas o corpo. Aqui o trabalho na saúde aproximase da dimensão de cidadania. Cidadania na medida em que saúde é uma questão de direito, direito à vida. A produção em saúde opera com a cidadania como possibilidade de vida, como potência de vida.

\section{Notas}

1 Usar a palavra "homem", neste texto, não significa considerála como uma categoria geral para definir todas as formas humanas, mas como um modo de indicar que, na própria formulação de direitos, já existe a conformação de uma figura existencial que seria utilizada de maneira homogeneizante.

2 É importante considerar, aqui, que na categoria raça é incluída uma derivada, que seria a pobreza.

3 Aqui se utiliza eugenia como uma racionalidade relativa à seleção e exclusão daquilo que se considera como bom e ruim, aquilo que permite um desenvolvimento mais saudável daquilo que o impede.

\section{Referências}

Agamben, G. (2007). Homo Sacer: o poder soberano e a vida nua I. Belo Horizonte: Editora UFMG.

Arendt, H. (1989). A condição humana. Rio de Janeiro: Forense.

Caponi, S. (2003). A saúde como abertura ao risco. In D. Czeresnia \& C. M. Freitas (Orgs.), Promoção de saúde: conceitos, reflexões, tendências (pp. 55-77). Rio de Janeiro: Fiocruz.
Castel, R. (2004). Las trampas de la exclusión: trabajo y utilidad social. Buenos Aires: Topía.

Czeresnia, D. (2003). O conceito de saúde e a diferença entre prevenção e promoção. In D. Czeresnia \& C. M. Freitas (Orgs.), Promoção de saúde: conceitos, reflexões, tendências (pp. 39-53). Rio de Janeiro: Fiocruz.

Deleuze, G. (2006). A ilha deserta: e outros textos. São Paulo: Iluminuras.

Deleuze, G. Spinoza. Cours Vincennes - 24/01/1978. Acesso em 07 de abril, 2008, de http://www.webdeleuze.com/php/texte. php cle $=194 \&$ groupe $=$ Spinoza\&langue $=5$

Foucault, M. (1999). História da sexualidade I: a vontade de saber. Rio de Janeiro: Graal.

Foucault, M. (2003a). A governamentalidade. In Ditos e escritos IV (pp. 281-305). Rio de Janeiro: Forense Universitária.

Foucault, M. (2003b). Poder e Saber. In Ditos e escritos IV (pp. 223-240). Rio de Janeiro: Forense Universitária.

Foucault, M. (2004). A ética do cuidado de si como prática de liberdade. In Ditos e escritos V (pp. 264-287). Rio de Janeiro: Forense Universitária.

Foucault, M. (2005). Em defesa da sociedade. São Paulo: Martins Fontes.

Hardt, M. (2003). O trabalho afetivo. In P. P. Pelbart \& R. Costa (Orgs.), Cadernos de subjetividade: o reencantamento do concreto (pp. 143-157). São Paulo: Hucitec.

Mattos, R. (2001). Os sentidos da integralidade: algumas reflexões acerca dos valores que devem ser defendidos. In R. Pinheiro \& R. Mattos (Orgs.), Os sentidos da integralidade na atenção e no cuidado à saúde (pp. 39-64). Rio de Janeiro: UERJ/IMS.

Nietzsche, F. (1998). Assim falou Zaratustra. Rio de Janeiro: Bertrand Brasil.

Ortega, F. (1999). Amizade e estética da existência em Foucault. Rio de Janeiro: Graal.

Pelbart, P. P. (2003). Vida Capital: ensaios de biopolítica. São Paulo: Iluminuras.

Pinheiro, R. (2004). Apresentação - democracia e saúde: sociedade civil, cidadania e cultura política. Physis, 14(1), 11-14.

Pinheiro, R. \& Guizardi, F. (2006). Cuidado e Integralidade: por uma genealogia de saberes e práticas no cotidiano. In R. Pinheiro \& R. Mattos (Orgs.), Cuidado: as fronteiras da integralidade (pp. 37-56). Rio de Janeiro: CEPES/URRJ, ABRASCO.

Presidência da República Federativa do Brasil. Lei n. 8.080, de 19 de setembro de 1990. (2005). Acesso em 03 de agosto, 2005, em https://www.planalto.gov.br/ccivil_03/leis/18080.htm

Secretaria Municipal de Saúde - Campinas, SP. Programa Paidéia: As Diretrizes da Secretaria Municipal de Saúde - Gestão 2001-2004. (2007). Acesso em 21 de junho, 2007, em http:// www.campinas.sp.gov.br/saude/diretrizes.htm

Recebido em: 28/06/2008

Revisão em: 17/04/2009

Aceite final em: 03/05/2009

Anita Guazzelli Bernardes é Psicóloga, Doutora em Psicologia pela Pontifícia Universidade Católica do RS, docente do Programa de Pós-graduação em Psicologia da Saúde da Universidade Católica Dom Bosco, Campo 
Grande, MT. Rua Abrão Júlio Rahe, 884, casa 1, Campo Grande, MS, CEP 79010-010 E-mail: anitabernardes@ig.com.br

Eduardo Cavalheiro Pelliccioli é Psicólogo, Mestre em Psicologia Social pela Pontifícia Universidade Católica do RS, docente da Universidade Federal do Mato Grosso do Sul. E-mail: edupelliccioli@yahoo.com

Neuza Maria de Fátima Guareschi é Psicóloga, $\mathrm{PhD}$ em Educação, Professora/Pesquisadora do Programa de Pós-graduação em Psicologia e Coordenadora do Grupo de Pesquisa Estudos Culturais e Modos de Subjetivação da Faculdade de Psicologia da Pontifícia Universidade Católica do Rio Grande do Sul. E-mail: nmguares@gmail.com

\section{Como citar:}

Bernardes, A.G., Pelliccioli, E. C., \& Guareschi, N. M. F. (2010). Trabalho e produção de saúde: práticas de liberdade e formas de governamentalidade. Psicologia \& Sociedade, 22(1), 5-13. 